\title{
OPTIMIZATION OF URBAN INFRASTRUCTURE SYSTEMS CONSIDERING THE ENVIRONMENTAL IMPACT AND THE COST
} 環境効果と経済性を考慮した都市社会基盤整備システムの最適化

\author{
Shunsuke MANAGI* and Hidefumi IMURA* \\ 馬奈木 俊介井村秀文
}

\begin{abstract}
This paper aims toward the development of the optimization model on the infrastructure systems. The model is attained by Investment Allocation Model (IAM), which has a sub model named as Technological Options Model (TOM). The TOM was developed in order to select the technology under restrictions. The best route for investment is presented by the IAM maximizing the welfare considering the environmental impact and the cost. The problem of the IAM is how to allocate investments among the various systems of regional infrastructure such as public transportation, sewerage and waste treatment. Within the limitations of a relatively simple model, the relation of the investment to minimize the damage and the investment to provide the benefit is demonstrated. Some case studies are shown as the flow and stock damage, respectively, which clearly indicate the patterns of each solution.
\end{abstract}

KEYWORDS : Optimization, Investment allocation model, Infrastructure systems, Damage function

\section{Introduction}

Various types of optimization models have been developed for planning infrastructure systems ${ }^{1,2,3}$. Their analysis uses a cost allocation framework for static analysis but not take environmental damage into account. However, the concept of accounting the damage is important because the damage provides a direct link between past policy decisions and currant decisions. From the viewpoint of above, the solution to the infrastructure's dynamic problem is a decision rule for investment as a function of the welfare over the relevant time horizon instead of only one decision for the dynamic problem of maximizing the effect or for the static problem of cost allocation.

This paper aims toward the development of the optimization model on the infrastructure systems. The model is attained by Investment Allocation Model (IAM), which has a sub model named as Technological Options Model (TOM). The TOM was developed in the author's previous study ${ }^{4}$ that used to select the technology under certain restrictions. The best route for investment is presented by the IAM maximizing the welfare that provides adequate balance for infrastructure provision. The problem of the IAM is how to allocate investments among the various systems of regional infrastructure such as public transportation, sewerage and waste treatment.

\section{A conceptual framework for optimization}

Fig. 1 shows the application of the IAM for the establishment of infrastructure. The system is configured to simulate based on the IAM in the whole process for dynamic analysis, while selecting the optimum technology by the TOM in each infrastructure system. Exogenous forces such as financial, environmental regulation and : allocation of weights affect the policy. However, evaluation data have different dimensions and characters. Ob-

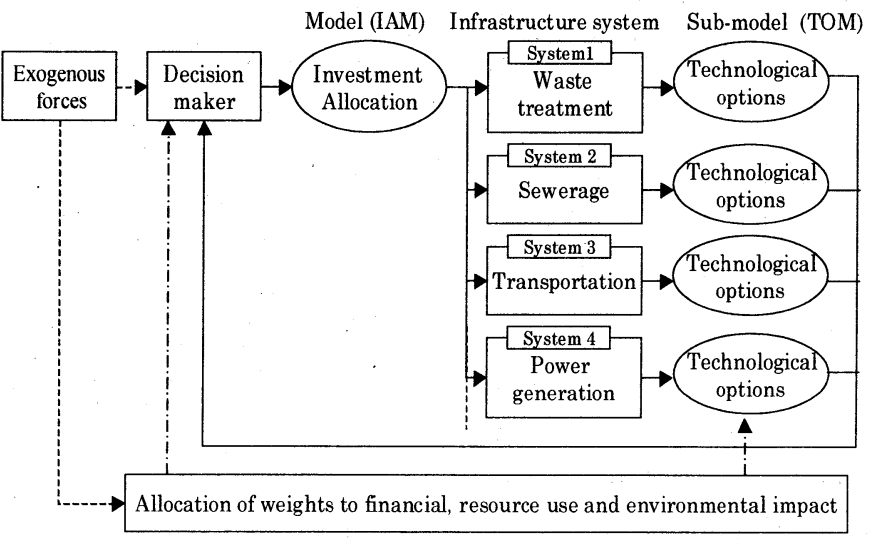

Fig.1. Application of the IAM for the establishment of infrastructure

\footnotetext{
* Institute of Environmental Systems, Faculty of Engineering, Kyushu University
} 
taining an unified index representing the whole data is difficult. In traditional methods, this is performed by weighting each evaluation result subjectively. In a previous study ${ }^{4}$, the allocation of weights was handled somewhat differently to allow for a more comprehensive sensitivity analysis.

Fig.2 illustrates the framework of the IAM. In this model, the IAM uses the outputs from the TOM such as the cost and the environmental impact in optimal technology.

\section{Technological Options Model}

The framework of the TOM is illustrated in Fig.3. It is necessary to select the best technology to consider both the environmental impact and the cost. The TOM is applied to the objective function, where cost and environmental impact can be minimized. Life Cycle $\mathrm{CO}_{2}\left(\mathrm{LC}-\mathrm{CO}_{2}\right)$, cost, processing capability and other parameters are used as the restrictive conditions.

The appropriate technologies are selected for consideration of above conditions. From the input about the technological information and area characteristic such as population density, the cost and environmental impact in optimal technology can be simulated. While there are many sectors in infrastructure, only the sewerage system was analyzed in the sub-model at present ${ }^{1}$.

\section{Investment Allocation Model}

\subsection{The model}

This section examines how a infrastructure system balances objectives of the effect of each investment and environmental damage, and how each investment balances in chronological order. The goal of the planning is to maximize the welfare $\mathrm{W}$, which is the discounted sum of utility $U_{t}$ from infrastructure provision, subject to the below constraints (Fig.4). Since the focus of this study is on infrastructure systems, we will assume that utility is simply the natural logarithm of $\mathrm{Y}_{\mathrm{ti}}-\mathrm{D}_{\mathrm{ti}}$ about infrastructure systems in the region.

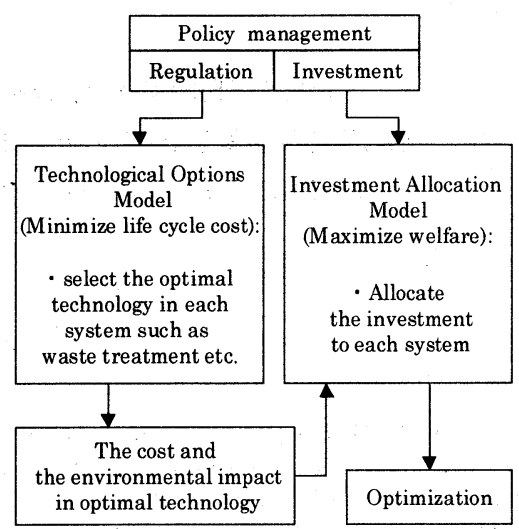

Fig.2. The framework of the IAM

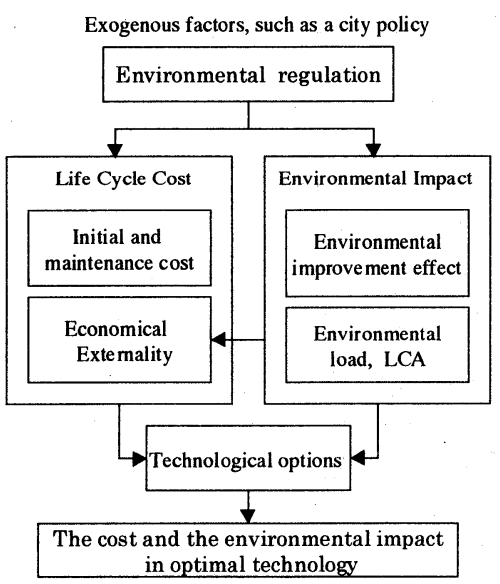

Fig.3. The framework of the TOM Where $Y_{t i}$ is benefit by the infrastructure provision, and $D_{t i}$ is environmental damage by not providing the infrastructure in each infrustructure i. Both $Y_{t i}$ and $D_{t i}$ are to be expressed in monetary value. The given discount rate is denoted $r$, and exogenous planning horizon is

T. It follows then that

$$
\begin{aligned}
& \text { Max: } \mathrm{W}=\Sigma_{\mathrm{t}} 1 /(1+\mathrm{r})^{\mathrm{t}} \times \mathrm{U}_{\mathrm{t}}, \\
& \mathrm{U}_{\mathrm{t}}=\Sigma_{\mathrm{i}} \log \left(\mathrm{Y}_{\mathrm{ti}}-\mathrm{D}_{\mathrm{ti}}\right)
\end{aligned}
$$

where the utility Ut is characterized by:

$$
\begin{aligned}
& \partial \mathrm{U}_{\mathrm{t}} /\left.\partial \mathrm{t}\right|_{\mathrm{Y}, \mathrm{D}}>0, \\
& \partial \mathrm{U}_{\mathrm{t}}{ }^{2} /\left.\partial \mathrm{t}^{2}\right|_{\mathrm{Y}, \mathrm{D}}<0
\end{aligned}
$$

This model aims to find an optimal investment allocation trend subject to given capital constraint $\mathrm{M}_{\mathrm{t}}$ at time $\mathrm{t}$. And the sum of other invests are thought of being grew every

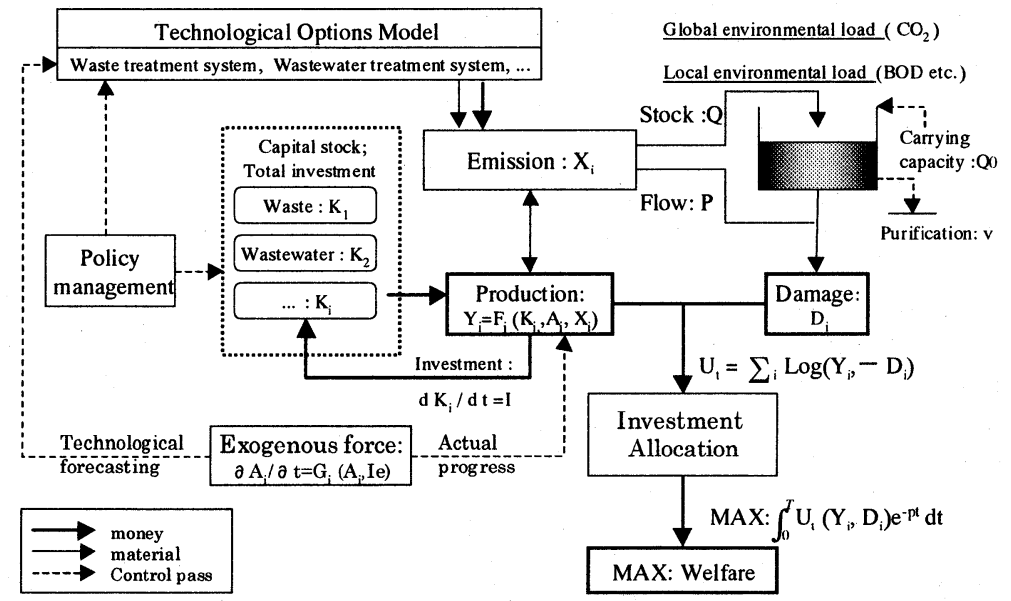

Fig.4. Investment Allocation Model (IAM) 
year with the economic development at rate $p . M_{0}$ is the capital at time $t=0$. Subject to the condition

$$
\begin{aligned}
& \mathrm{M}_{\mathrm{t}}=\sum_{\mathrm{i}} \mathrm{I}_{\mathrm{ti}}=(1+\mathrm{p})^{\mathrm{t}} \mathrm{M}_{0} \\
& \mathrm{~K}_{\mathrm{t}+\mathrm{i}}=\mathrm{K}_{\mathrm{ti}}+\mathrm{I}_{\mathrm{ti}}
\end{aligned}
$$

$K_{t i}$ denotes the capital stock of each infrastructure system of $I_{t i}$, while $I_{t i}$ stands for the corresponding investment.

$\mathrm{X}_{\mathrm{tij}}$ denotes a capacity of the infrastructure system accompanied by the provision. $\mathrm{X}_{\mathrm{tij}}$ involves the treatment quantity in each substance $j$. The effect to $X_{t i j}$ depends on investment $I_{t i j}$ and the cost of each technology $\mathrm{C}_{\mathrm{ti}} . \alpha_{\mathrm{ij}}$ is a technical efficiency constant. $\mathrm{C}_{\mathrm{ti}}$ and $\alpha_{\mathrm{ij}}$ are came from the result of the TOM. Feasibility implies that $\mathrm{X}_{\mathrm{tij}} \geqq 0$ for $\mathrm{t} \geqq 0$, Consequently

$$
\mathrm{X}_{\mathrm{tij}}=\mathrm{X}_{\mathrm{t}-\mathrm{ij}}+\alpha_{\mathrm{ij}} \times \mathrm{I}_{\mathrm{ti}} / \mathrm{C}_{\mathrm{ti}}
$$

Customarily, aggregate production function is defined as the output obtainable from various amounts of capital and labor, at a given fixed level of knowledge. Then, at a later stage, technological progress is introduced.

Here it will be more effective to add the environmental benefit. Let $F_{t i}$ denote the aggregate provision function made up with $\mathrm{K}_{\mathrm{t}}, \mathrm{A}_{\mathrm{ti}}$ and $\mathrm{X}_{\mathrm{tij}}$. $\mathrm{Y}_{\mathrm{ti}}$ means benefit from provision include technological progress and environmental benefit such as water treatment in this formulation. The $\mathrm{Y}_{\mathrm{ti}}$ is then given as

$$
\mathrm{Y}_{\mathrm{ti}}=\mathrm{F}_{\mathrm{ti}}\left(\mathrm{K}_{\mathrm{ti}}, \mathrm{A}_{\mathrm{ti}}, \mathrm{X}_{\mathrm{tij}}\right)
$$

Anticipated technological change is modeled as follows. The factor Ati stands for the state of knowledge of technology, which influences the TOM and $Y_{t i}$. Formulation of $A_{t i}$ is used to determine the pace of technological progress as an exogenous force, then taken the form ${ }^{5}$,

$$
\partial \mathrm{A}_{\mathrm{ti}} / \partial \mathrm{t}=\mathrm{G}_{\mathrm{ti}}\left(\mathrm{A}_{\mathrm{ti}}, \mathrm{I}_{\mathrm{eti}}\right)
$$

Ieti is the investment for the technology of infrastructure $i$ in time $t$, determined as an exogenous force. Over time, knowledge is incremented by new ideas, just as capital is incremented by new investments. It is assumed that some typical trend in Ieti for the infrastructure technologies. It is possible to provide the technological forecasting model for applying the existing models ${ }^{6,7,8}$ about technology.

To simulate the relationship between emissions and economic damage it is necessary to specify, on the one hand, how emissions accumulates in the environment, and to evaluate, on the other, how an increased emissions stock feeds back into production. When the damage is considered, there are two-style damage of flow $(\mathrm{Dp})$ and stock $(\mathrm{Dq})$. The influence of flow damage appears at the generation period, and the damage is proportional to the concentration of environmental load. The environmental load such as $\mathrm{CO}_{2}$ assumes the damage does not occur until the amount of the pollution accumulation exceeds carrying capacity. Once damage occurs, generally, the damage at that time is large. This is the case of stock damage.

$P_{t i}$ is a measure of the environmental pollution such as BOD that is influenced by the $X_{t i}$ And $P_{0}$ is the pollution at time $t=0, f_{t i j}$ is the purification capability of each technology that came from the result of the TOM.

$$
\mathrm{P}_{\mathrm{tij}}=\mathrm{P}_{0}-\mathrm{f}_{\mathrm{tij}} \times \mathrm{X}_{\mathrm{tij}}
$$

When $P_{t i j}$ is the LCA, $P_{t i j}$ is directly influenced by the $\mathrm{I}_{t i} . \quad \beta_{\mathrm{ij}}$ is a technical efficiency constant that came from the result of the TOM.

$$
P_{t i j}=P_{t-1 i j}+\beta_{i j} \times I_{t i} / C_{t i}
$$

We shall imagine that the planning board is concerned with the pace of extraction of the resource indicated as LCA (of size $\mathrm{S}_{0}$ at $\mathrm{t}=0$ ) with a view to maximizing the present discounted value of the welfare. We are, then, supposing that the resource is socially managed.

$$
\mathrm{P}_{\mathrm{tij}} \leqq \mathrm{S}_{0}
$$

Flow damage Dp emerges always when there is pollution, and dio and $d_{i 1}$ are the flow damage coefficient.

$$
\operatorname{Dp}\left(\mathrm{P}_{\mathrm{tij}}\right)=\mathrm{d}_{\mathrm{i} 0} \times \mathrm{P}_{\mathrm{tij}}{ }^{\mathrm{d}}
$$

$Q_{t i j}$ is the stock of pollutants. The laws of nature influence the accumulation of pollution in the environ- 
ment. $v_{i}\left(a_{i j}, b_{i j}, c_{i j}, P_{t i j}\right)$ denotes the natural losses and self-purification processes, which can be formulated by biological, physical, chemical characteristic or method and pollution indicated as $a_{i j}, b_{i j}, c_{i j}$ and $P_{t i j}$, respectively. We assume that $v_{j}\left(P_{t i j}\right)$ is twice continuously differentiable and concave, as well as decreasing in $P_{t i j}$. The equation assumes that such processes are linearly related to pollution. The growth path of the pollution stock can be expressed as:

$$
Q_{t i j}=\left(1-v_{j}\left(a_{i j}, b_{j}, c_{j}, P_{t i j}\right)\right) Q_{t-1 i j}+P_{t i j}
$$

When the pollution stock reaches the carrying capacity in the environment $Q_{0}$ at time $t$, stock damage Dq emerges. $D_{i 0}, d_{i 2}$ is the stock damage coefficient and multiplier, respectively. We assume $D_{q}\left(Q_{\mathrm{tij}_{\mathrm{i}}}\right)=0$ for $0<Q_{\mathrm{tij}}<Q_{j \mathrm{jo}}$, and $\mathrm{Dq}\left(\mathrm{Q}_{\mathrm{tij}}\right)$ is twice continuously differentiable, increasing in $Q_{\mathrm{tij}}$ as well as strictly convex for $Q_{\mathrm{tij}}>Q_{j 0}$. Thus the Dq is convex when the pollution stock exceeds $Q_{j 0}$.

$$
\operatorname{Dq}\left(Q_{\mathrm{tij}}\right)=D_{\mathrm{io}}\left(1-Q_{\mathrm{tij}} / Q_{\mathrm{j} j}\right)^{\mathrm{d}_{i 2}}
$$

The total damage is the sum of flow and stock damage,

$$
\mathrm{D}_{\mathrm{ti}}=\sum_{j}\left(\mathrm{Dp}\left(\mathrm{P}_{\mathrm{tij}}\right)+\mathrm{Dq}\left(\mathrm{Q}_{\mathrm{tij}}\right)\right)
$$

The quantity and monetary value of environmental service flows, however, are often unknown and difficult to measure, largely affected by society's awareness regarding the preservation of environmental resources. The coefficient $d_{i 0}, D_{j 0}$ and $d_{j 1,2}$ of course lead to the formulation and application of policies that change the pattern of pollution both within a region and across the globe.

\subsection{Case study}

(1) The influence of flow and stock damage

The benefit and the damage of two different kinds of infrastructure, system 1 and system 2, are simulated by the IAM. The length of the time horizon is $\mathrm{T}=30$.

1) Flow damage (Case 1)

This case treats flow damage Dp and ignores the stock damage Dq. Fig.5 shows the characteristic of benefit $\mathrm{Y}$ and damage $\mathrm{D}$ of system 1, 2 respectively. The benefit of system 1 is much lower, but the damage is much bigger than that of system 2 when provision does not progress.

As a result of simulation, the index representing the share of X, D, I is shown in Fig.6. The investments for systems 1 have priority in the first periods. But gradually, the investments getting less because of the losses of the damage. The other invest is getting more. It will be get the most socially effective based on the above investing allocation. This case shows that it is optimum to suppress damage by early sufficient investment. The equations and the coefficient used in this case to show the typical case for suppressing the flow damage are indicated below.

$$
\mathrm{r}=.02, \mathrm{p}=.02, \mathrm{v}_{1}=.6, \mathrm{~d}_{10}=.09, \mathrm{~d}_{20}=.0009, \mathrm{~d}_{11}=2.5, \mathrm{~d}_{21}=3 ., \mathrm{Y}=1.2 \mathrm{~K}^{0.3} \mathrm{X}^{0.7}, \mathrm{Y}=1.5 \mathrm{~K}^{0.1} \mathrm{X}^{0.9} \text {. }
$$

2) Stock damage (Case 2)

This case treats stock damage Dq in system 1 and flow damage Dp in system 2 . Fid. 7 shows the characteristic of benefit $\mathrm{Y}$ and damage $\mathrm{D}$ of system 1,2 respectively. The productive ability of system 1 is much lower, but the damage is much bigger than that of system 2 when the pollution stock exceeds Qjo.

As a result of simulation, the index representing the share of investment for the boss systems are shown in Fig.8. The investment for system 2 has priority in the first periods. In the middle periods, however, with the pollution stock is getting more, the environment investment using preventing the environmental losses should be improved. In the finally periods, because make the losses influence getting less due to the environment invest in the middle stage, the other invest is getting more. It will be get the most social effective based on the above investing allocation. By performing suitable investment for suitable time, the welfare is made to the maximizing under assumptions to show the typical case for suppressing the stock damage indicated below.

$$
\mathrm{r}=.02, \mathrm{p}=.02, \mathrm{v}_{1}=.6, \mathrm{D}_{10}=.9, \mathrm{~d}_{20}=.00009, \mathrm{~d}_{12}=1.3, \mathrm{~d}_{21}=1.1, \mathrm{Q}_{\mathrm{j} 0}=3500, \mathrm{Y}=1.2 \mathrm{~K}^{0.3} \mathrm{X}^{0.7}, \mathrm{Y}=1.5 \mathrm{~K}^{0.1} \mathrm{X}^{0.9} \text {. }
$$

The presented results of these two cases are quite typical in the influence of flow and stock damage. This model enables it to show complex and unclear investment allocation concretely in dynamic, even though the simulation always needs to orbital correction because of the uncertainty. As for flow damage, the results show that it is the optimum to suppress flow damage by early sufficient investment even though the benefit from provision is low. As for stock damage, the results show that it is the optimum to suppress stock damage by middle period's sufficient investment even though the benefit from provision is low. 


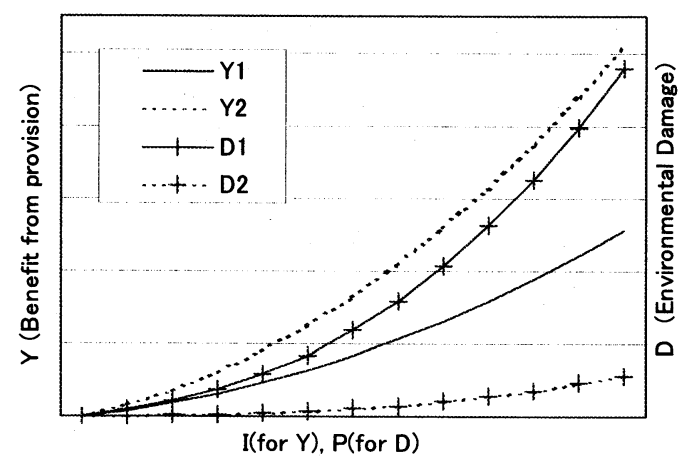

Fig.5. The characteristic of the each system

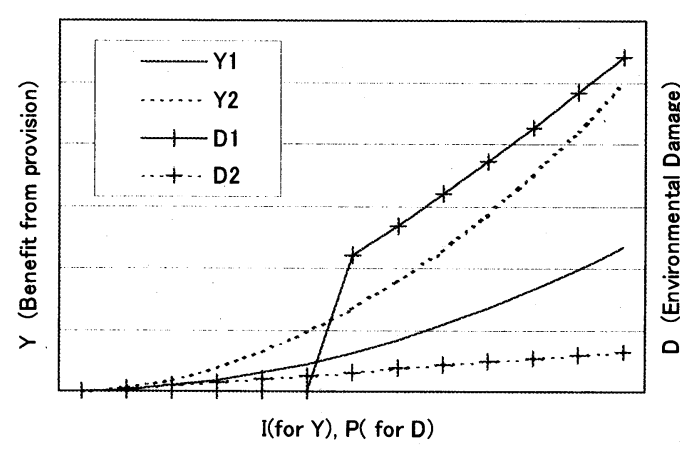

Fig.7. The characteristic of the each system

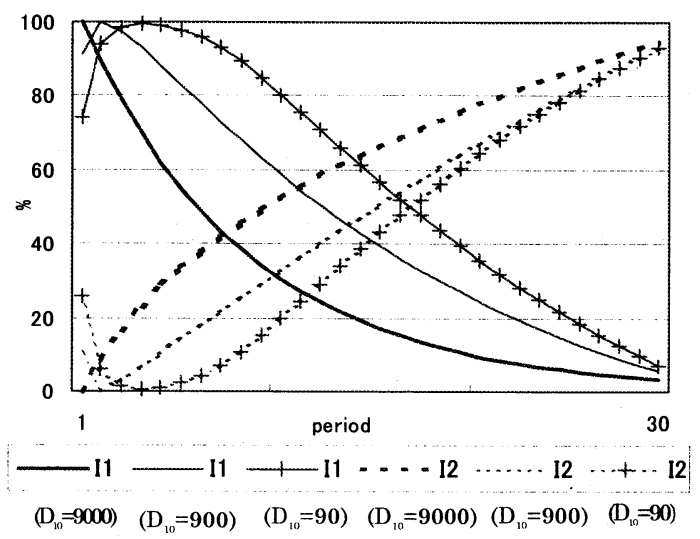

Fig.9. Investment allocation rate by the change of damage function parameter

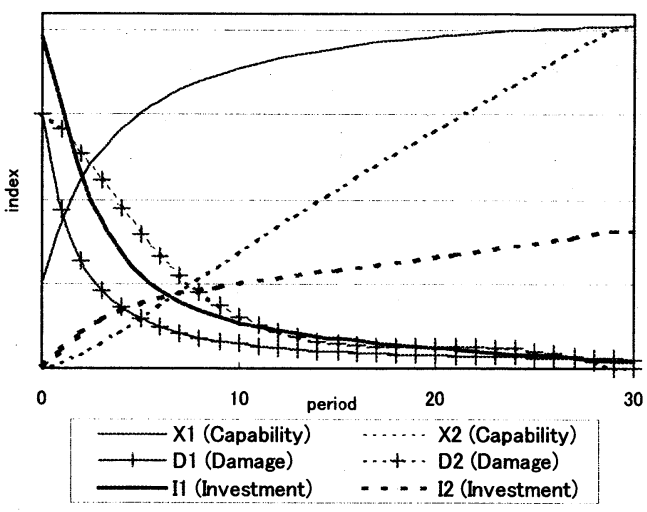

Fig.6. The solution to the flow damage

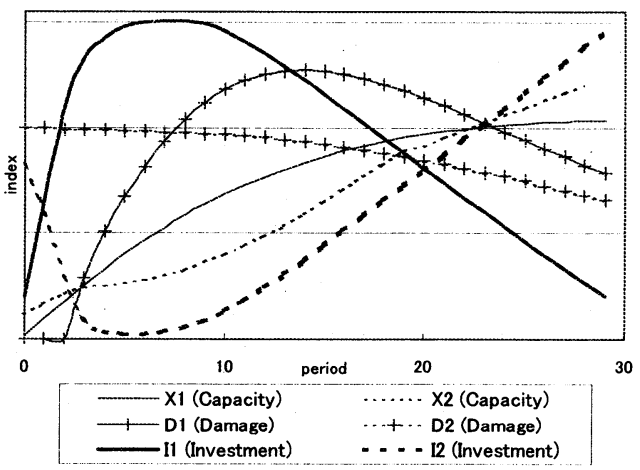

Fig.8. The solution to the stock damage

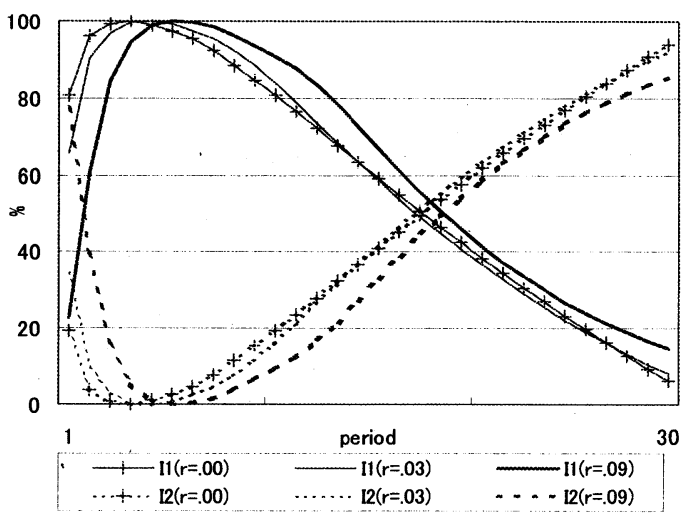

Fig.10. Investment allocation rate by the change of discount rate

(2) The influence of parameter change in damage function (Case 3)

As a next case study, some coefficient changes of damage function are considered as typical problems of determining the damage function. The characteristics of system 1 and system 2 are assumed to be same to Case 2 except $D_{10}$. This case examines how the environmental investment for system 1 changes to balance objectives of benefit and environmental damage.

As a result of simulation, Fig.9 shows the three cases. In the case of $D_{10}=90$, the investment for system 1 has a sharp increase in the first periods even though the effects of Y2 is bigger than Y1, but then we see a sharp fall in $\mathrm{I} 1$. In the case of $\mathrm{D}_{10}=9000$, the investment for system 1 has a priority in the first periods, but 
then we see a sharp fall in I1. This is for the reason that the enough I1 in the first periods is necessary to suppress the damages. With a higher coefficient, it is optimal to shift part of the investment for benefit from the provision (investment for system 2) into the future, and investment to suppress the damage (investment for system 1) is given priority in the first periods.

(3) The effects of change in the discount rate (Case 4)

In many theoretical model a higher discount rate implies a faster exhaustion of the resource, which is equivalent to the neglecting of the environmental damages here.

To obtain the results shown in Fig.10, we carry out the optimization procedure using different discount rates, with all other coefficients held constants, which is same as that of case 2 except $D_{10}\left(D_{10}=9\right)$. An increase in the discount rate implies a reduction of investment to suppress the damage (investment for system 1) in the first periods, since the effect of suppressing the damages becomes small. With a higher discount rate, it is optimal to shift part of the investment to suppress the damage into the future, and investment for benefit the provision (investment for system 2) is given priority in the first periods. In order to favor environmental projects with benefits that appear in the long run, it has been suggested that lower discount rate be used.

\section{Conclusion}

The objective in this study is to show a methodology that might be useful for policy maker to plan the urban infrastructure provision by dynamic investment allocation. The model proposed here, while not easy to set parameter of functions, deals directly with two major difficulties in infrastructure systems; allowing for the value judgments of allocating investments and technologies. In summary, the model proposed here has three main advantages:

1). It provides a logical and systematic template for dynamic Investment Allocation Model (IAM) that serves to guide the policy maker. Many different environmental impacts and economic effect in infrastructure systems can be combined in a same flame.

2). It provides a consistent structure for Technological Options Model (TOM) in each infrastructure system considering the environmental impact and the cost.

3). Maximizing of welfare function is the objective function of the model, which treat benefit and environmental damage. The damage function is divided into two influences of stock and flow.

Within the limitations of a relatively simple model, the relation of the investment to suppress the damage and the investment to provide the benefit is demonstrated. Some case studies are shown as the flow and stock damage, respectively, which clearly indicate the patterns of each solution.

It is hoped that this model will finds application in the planning and funding of urban infrastructure project in developing countries like China by providing a way of allocating investments, because the improvement of infrastructures is delayed in those areas. Although every technology needs not only energy but also cause different environmental loads, the expense loss and environmental impacts can be minimized by using the most appropriate technology under different conditions in appropriate time.

Further research is needed to explore the each infrastructure systems except for sewerage system, survey to estimate the value of the environmental benefits and damages to residents, and examine actual data of investment allocation.

\section{Acknowledgements}

The authors would like to thank Mr. Toru Matsumoto and Dr. Ryo Fujikura for helpful comments and suggestions.

\section{References}

1. Loughlin, J.C., The Efficiency and Equity of Cost Allocation Methods for Multipurpose Water Project, Water Resour. Res., 13(1), 8-14,1977

2. Loehman, E., Orlando, J., Tschirhart, J. and Whinston, A., Cost Allocation for a Regional Wastewater Treatment Systems, Water Resour. Res., 15, 193-202,1979

3. Watkins, A.R., Cost Allocation in Urban Infrastructure Funding, J. Urban Plng. and Devel.,124(1), 44-53,1998

4. Managi,S., Matsumoto,T. and Imura,H., Optimization of Sewerage System in Urban Areas Considering the Environmental Impact and the Cost, Juurnal of environmental systems and engineering, Japan Society of Civil Engineers (in submission)

5. Romer,P.M.,Increasing Returns and Long-Run Growth, Journal of Political Economy, 94, 1002-1037, 1986

6. Kang, B., Kim, H., Han, C. and Yim, C., A Demand-based Model for Forecasting Innovation Diffusion, Computers\&Industrial Engineering, 30(3), 487-499, 1996

7. Bhargava, S.C., A Generalized Form of the Fisher-Pry Model of Technological Substitution, Technol. Forecast. Soc. Change 49, 27-33, 1995

8. Islam, T., Meade, N., The Diffusion of Successive Generations of a Technology: A More General Model, Technol. Forecast. Soc. Change 56, 49-60, 1997 